\title{
Inter and intra-reliability of ultrasonography for the measurement of abdominal subcutaneous \& visceral adipose tissue thickness at 12 weeks gestation
}

\author{
Alexandra Cremona ${ }^{1,2,3,4,5^{*}}$ (D, Kevin Hayes ${ }^{6}$, Clodagh S. O'Gorman ${ }^{1,4}$, Ciara Ní Laighin ${ }^{1,7}$, Khadijah I. Ismail ${ }^{1,7}$,
} Alan E. Donnelly ${ }^{4,5}$, Jill Hamilton ${ }^{8}$ and Amanda Cotter ${ }^{1,7}$

\begin{abstract}
Background: Excess abdominal adiposity cause metabolic disturbances, particularly in pregnancy. Methods of accurate measurement are limited in pregnancy due to risks associated with these procedures. This study outlines a non-invasive methodology for the measurement of adipose tissue in pregnancy and determines the intra- and inter-observer reliability of ultrasound (US) measurements of the two components of adipose tissue (subcutaneous (SAT) and visceral adipose tissue (VAT)) within a pregnant population.

Methods: Thirty pregnant women were recruited at the end of their first trimester, from routine antenatal clinic at the University Maternity Hospital Limerick, Ireland. Measurements of adipose tissue thickness were obtained using a GE Voluson E8 employing a 1-5 MHz curvilinear array transducer. Two observers, employing methodological rigour in US technique, measured thickness of adipose tissue three times, and segmented the US image systematically in order to define measurements of SAT and VAT using specifically pre-defined anatomical landmarks.

Results: Intra-observer and inter-observer precision was assessed using Coefficient of Variation (CV). Measurements of SAT and total adipose for both observers were $<5 \%$ CV and $<10 \%$ CV for VAT in measures by both observers. Inter-observer reliability was assessed by Limits of Agreement (LOA). LoA were determined to be -0.45 to $0.46 \mathrm{~cm}$ for SAT and -0.34 to $0.53 \mathrm{~cm}$ for VAT values. Systematic bias of SAT measurement was $0.01 \mathrm{~cm}$ and $0.10 \mathrm{~cm}$ for VAT. Inter-observer precision was also assessed by coefficient of variation (CV: SAT, 3.1\%; VAT, 7.2\%; Total adipose, 3.0\%).

Conclusion: Intra-observer precision was found to be acceptable for measures of SAT, VAT and total adipose according to anthropometric criterion, with higher precision reported in SAT values than in VAT. Inter-observer reliability assessed by Limits-Of-Agreement (LoA) confirm anthropometrically reliable to $0.5 \mathrm{~cm}$. Systematic bias was minimal for both measures, falling within 95\% confidence intervals. These results suggest that US can produce reliable, repeatable and accurate measures of SAT and VAT during pregnancy.
\end{abstract}

Keywords: Adipose, Visceral, Reliability, Ultrasound, Technique, Pregnancy, Subcutaneous, Body composition

\footnotetext{
* Correspondence: alexandra.cremona@ul.ie

${ }^{1}$ Graduate Entry Medical School (GEMS), University of Limerick, Limerick, Ireland

${ }^{2}$ School of Allied Health (SAH), University of Limerick, Limerick, Ireland

Full list of author information is available at the end of the article
}

(c) The Author(s). 2019 Open Access This article is distributed under the terms of the Creative Commons Attribution 4.0 International License (http://creativecommons.org/licenses/by/4.0/), which permits unrestricted use, distribution, and reproduction in any medium, provided you give appropriate credit to the original author(s) and the source, provide a link to the Creative Commons license, and indicate if changes were made. The Creative Commons Public Domain Dedication waiver (http://creativecommons.org/publicdomain/zero/1.0/) applies to the data made available in this article, unless otherwise stated. 


\section{Background}

Ultrasound (US) has been used effectively to assess body fat for decades [1]. Limitations to its use are due to lack of standardization of technique, and data on repeatability amongst different operators [2, 3]. The current gold standard for the quantitative assessment of intraabdominal adipose tissue uses computed tomography (CT) scanning [4]. Validity and reproducibility of ultrasound techniques against CT scanning has been previously assessed [5-8] in non-pregnant populations, and reportedly the inter-observer correlation coefficient of the mean ultrasound distance was $0.94(P<0.001)$, and coefficient of variation $5.4 \%$ within a non-pregnant population [7]. Other methods for quantifying risk using abdominal measures and ratios of these, are; DXA scanning, waist: hip circumference ratio, and anthropometric skinfold measurements. However, during pregnancy these three techniques have distinct disadvantages, which render them inadequate within a clinical setting and in a pregnant population $[9,10]$. Limitations include exposure to ionising radiation, expense, lack of validation of technique, time-consuming techniques and requirement of a trained skilful measurer $[9,10]$.

Despite methods of capturing body composition being limited within a pregnant population, the use of ultrasound to measure abdominal adipose tissue has been recently reviewed and found to be a useful tool for measuring body composition non-invasively $[2,3]$. While US requires skill and training with a cost implication, pregnant women undergo US by a skilled ultrasonographer at the end of the first trimester, as part of routine care, making this a contact point with healthcare professionals with potential opportunity for measurements to be carried out. Measuring components of abdominal adipose tissue- visceral adipose tissue (VAT) and subcutaneous adipose tissue (SAT), are of particular current relevance and importance as these depots of adiposity have been implicated in the pathogenesis of metabolic and cardiovascular health in non-pregnant populations $[3,11,12]$, as well as in a pregnant population [13].

Maternal obesity has been linked to increased morbidity and mortality in pregnancy putting both the mother and infant at risk in the short and long term [14, 15]. Large population studies looking at pregnancy outcomes based on the World Health Organisation (WHO) body mass index (BMI) sub-classifications of obesity [16] found a relationship to increasing risk of adverse outcomes, including gestational diabetes, hypertensive disorders, caesarean section, macrosomia, admission to neonatal unit and neonatal hypoglycaemia $[15,17,18]$. However, BMI does not provide insight into components of body composition, such as lean tissue, subcutaneous or visceral adipose tissue which are known to exert different physiological effects in the pregnancy state [19]. Crude measures of adipose thickness such as that possible via ultrasound, provide a non-invasive technique for insight into subcutaneous and visceral adipose compartments of body composition. It is understood that visceral fat, specifically pre-peritoneal fat thickness, has been identified in the production of excess adipokines which play a role in increased insulin resistance by disrupting post-insulin signalling mechanisms, thus contributing to the pathogensis of gestational diabetes mellitus $[20,21]$. It has also been associated with an increase in other cardio-metabolic risk factors within various studies [12, 22-24]. The role of subcutaneous fat in the development of obesity related disorders remains controversial according to a recent review by Bazzocchi, et al. [3]. The review attributes contradictory findings from investigations of subcutaneous fat $[25,26]$, to the variation in location of the measurement and lack of consistency in the methods used to capture this specific depot of adipose [27].

To be clinically useful within a pregnant population, reliability and reproducibility of abdominal fat quantification needed to be assessed within this specific population. Therefore, this study sought to standardise and outline a technically rigorous methodology used to quantify abdominal adipose tissue in pregnant women, and to segment this into its constituents, visceral (VAT) measured as the pre-peritoneal fat thickness, and subcutaneous adipose tissue (SAT) as the minimum abdominal subcutaneous fat thickness. Subsequently, both inter- and intra-observer variability were assessed in order to test the reliability of these measures in a pregnant population.

\section{Methods \\ Study population}

Thirty subjects were recruited prospectively. These subjects were attending the University Maternity Hospital Limerick (Ireland) for their first routine antenatal visit at 12-weeks gestation, at which an ultrasound scan is routinely performed. Informed consent was sought and granted (REC 082/17) in accordance with the ethical recommendations of Health Service Executive (HSE) Mid Western Hospital Research Ethics Committee.

\section{Ultrasonography}

Measurements of adipose tissue were taken via abdominal ultrasonography (US) using a GE Voluson E8 employing a $1-5 \mathrm{MHz}$ curvilinear array transducer. This transducer was a practical choice as it required no changeover from the preceding obstetric scan, and the frequency was sufficiently high to provide adequate resolution at the shallow depth of measurement. 
With the patient in a supine position and the transducer perpendicular to the skin, the required image was obtained in sagittal plane at the xiphisternum, producing a longitudinal view of the left lobe of liver and the aorta (see Fig. 1). Minimal pressure was exerted on the skin, in order to avoid compression of the adipose tissue. The transducer was rocked left to right, in order to identify the narrowest projection of the linea alba. The scan depth was reduced; excluding the aorta from the image. The sector width was reduced to 40 degrees; increasing line density. Thus, an image of both layers of adipose tissue was obtained with the inferior part of the left lobe of liver seen posteriorly (see Fig. 2a and b). At this point, the time gain compensation (TGC) and overall gain were adjusted carefully to allow clear visualisation of subcutaneous adipose tissue and homogenous echogenicity within the left lobe of liver. The image was then frozen.

Calipers were placed to measure in millimetres. Subcutaneous fatty tissue was measured from the lower border of the cutaneous layer to the upper border of the linea alba and visceral fatty tissue was measured from the lower border of linea alba to the upper border of the liver capsule.

The US measurements were performed at the time of routine first trimester ultrasound examination. Both observers took 3 measurements each of both VAT and SAT on 30 subjects. A new image was acquired between each set of measurements. The second observer entered the examination room once the first observer's measurements were completed and removed from the screen. All six images were saved using ViewPoint ${ }^{\mathrm{m}}{ }^{\mathrm{m}}$, GE's ultrasound image management and reporting solution software and were identified with each observers' initials prior to transfer. Measurements recorded by observer 1 where undertaken by an obstetrician, and measurements by observer 2 where undertaken by a trained radiographer. Both observers were regularly involved in antenatal scanning at this clinical site.

\section{Statistical methods}

SAT and VAT on 30 subjects were obtained by two observers, (coded here as $\mathrm{K}$ and $\mathrm{C}$ ). Each measurement was replicated 3 times, (with the exception of one occasion where observer $\mathrm{K}$ made just two replicate measurements of subcutaneous fat on a particular subject).

Intra-observer precision was assessed using Coefficientof-Variation (Table 1). Inter-observer reliability was assessed using Coefficient-of-variation, and precision expressed as repeatability standard deviations (SD) and their respective coefficients, as well as Limits-of-Agreement. Graphical comparisons of the measurements obtained by the two observers were made using Bland-Altman plots showing unlinked replicates [28]. These were generated using the method comparison studies $R$ package MethComp [29] which determines the LoA by fitting a variance component model that assumes unlinked replicates [30]. Comparison plots were constructed (see Figs. 3a, b and 4a, b). Estimates of the LoA were obtained from the corresponding variance component model.

\section{Results}

Intra-observer precision was assessed by co-efficient of variation. The data are presented in Table 1. Intraobserver precision was to an acceptable degree according to anthropometric criterion. Measurements of SAT

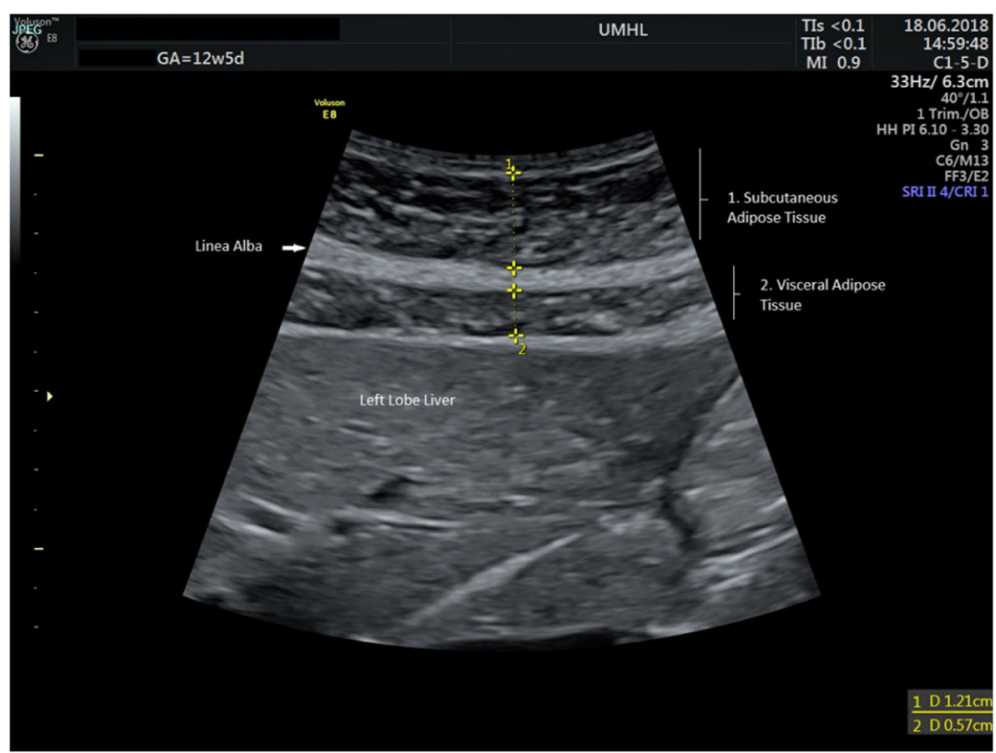

Fig. 1 Example ultrasound screenshot image at correct position for measurement of SAT (1) and VAT (2) 
a

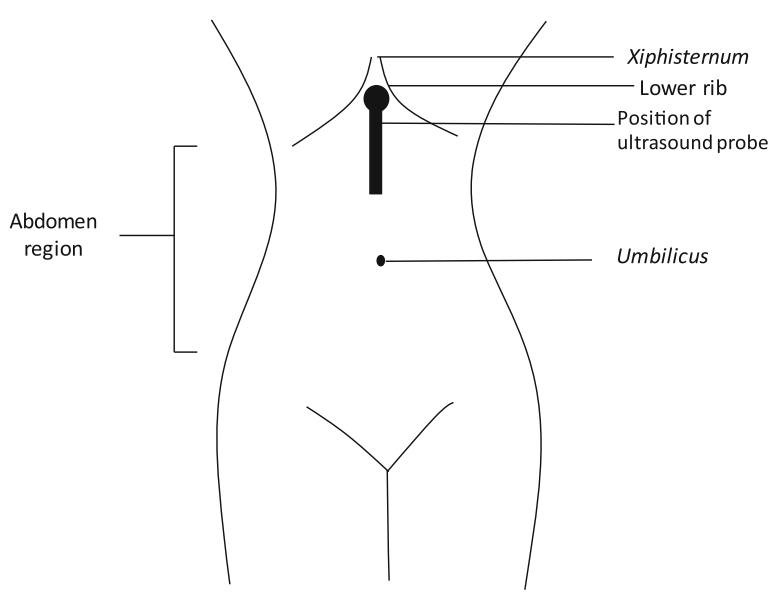

b

ANTERIOR

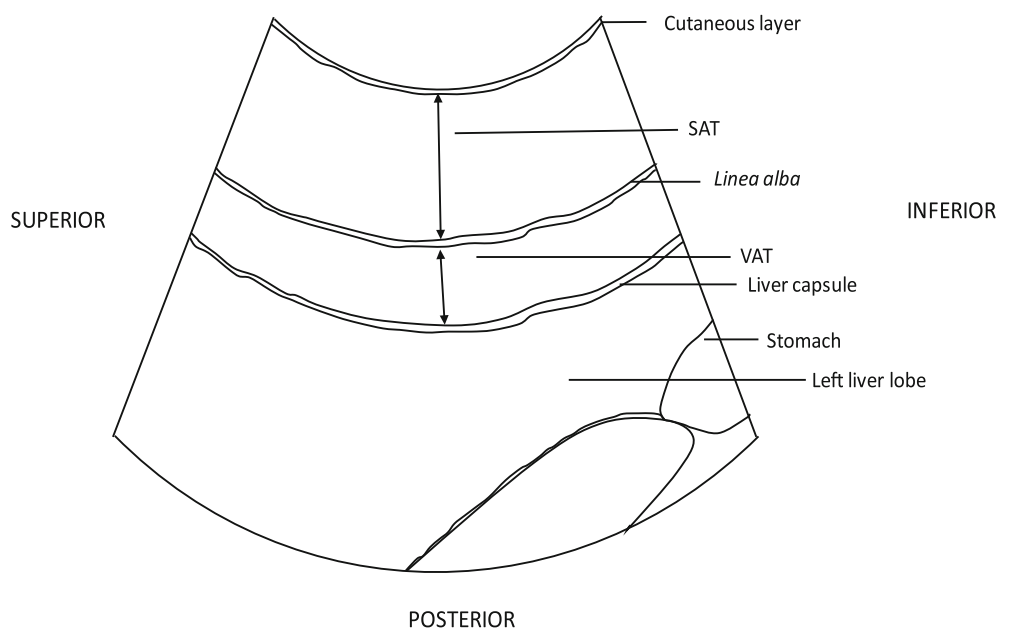

Fig. 2 a Anatomical schematic representation of xiphisternum in relation to positioning of ultrasound probe. $\mathbf{b}$ Anatomical schematic of ultrasound image to illustrate anatomical landmarks and positioning. SAT Subcutaneous Adipose Tissue; VAT Visceral Adipose Tissue (pre-peritoneal fat)

and total adipose for both observers was $<5 \% \mathrm{CV}$ and level for VAT $<10 \%$ CV for both observers.

Inter-observer precision and repeatability was also assessed by co-efficient of variation, with \%CV of 3.05, 7.15 and $2.95 \%$ for SAT, VAT and total adipose respectively. Inter-observer repeatability standard deviations and coefficients are presented in Table 2.

Table 1 Coefficient of variation (CV) for observer 1 and observer 2 based on triplicate measures of SAT, VAT and total adipose $($ SAT + VAT) on replicates $(n=30)$

\begin{tabular}{|c|c|c|c|c|}
\hline \multirow[b]{2}{*}{ Thickness (cm) } & \multicolumn{2}{|l|}{ Observer 1} & \multicolumn{2}{|l|}{ Observer 2} \\
\hline & Mean $( \pm S D)$ & $\overline{\% C V}$ & Mean $( \pm$ SD) & $\% \mathrm{CV}$ \\
\hline SAT & $1.5 \pm 0.1$ & 2.6 & $1.5 \pm 0.1$ & 3.5 \\
\hline VAT & $1.0 \pm 0.1$ & 5.8 & $0.9 \pm 0.1$ & 8.5 \\
\hline Total adipose & $2.5 \pm 0.1$ & 2.6 & $2.4 \pm 0.1$ & 3.3 \\
\hline
\end{tabular}

Inter-observer reliability was also assessed by LoA. Determinations by each of the two observers was made in triplicate. LoA were determined to be -0.45 to $0.46 \mathrm{~cm}$ for SAT and -0.34 to $0.53 \mathrm{~cm}$ for VAT values. Systematic bias of SAT measurement was $0.01 \mathrm{~cm}$ and VAT, $0.10 \mathrm{~cm}(p>0.05)$.

\section{Discussion}

The results of this reliability study show that intraabdominal ultrasound, using a strict protocol, is a reliable method to assess the amount of subcutaneous and visceral adipose tissue. Within the same operator, intraobserver precision is acceptable for measures of SAT, VAT and total adipose, with higher precision in SAT values than VAT. Between different operators, interobserver reliability assessed by LoA confirm anthropometrically reliable to $0.5 \mathrm{~cm}$. Systematic bias was 

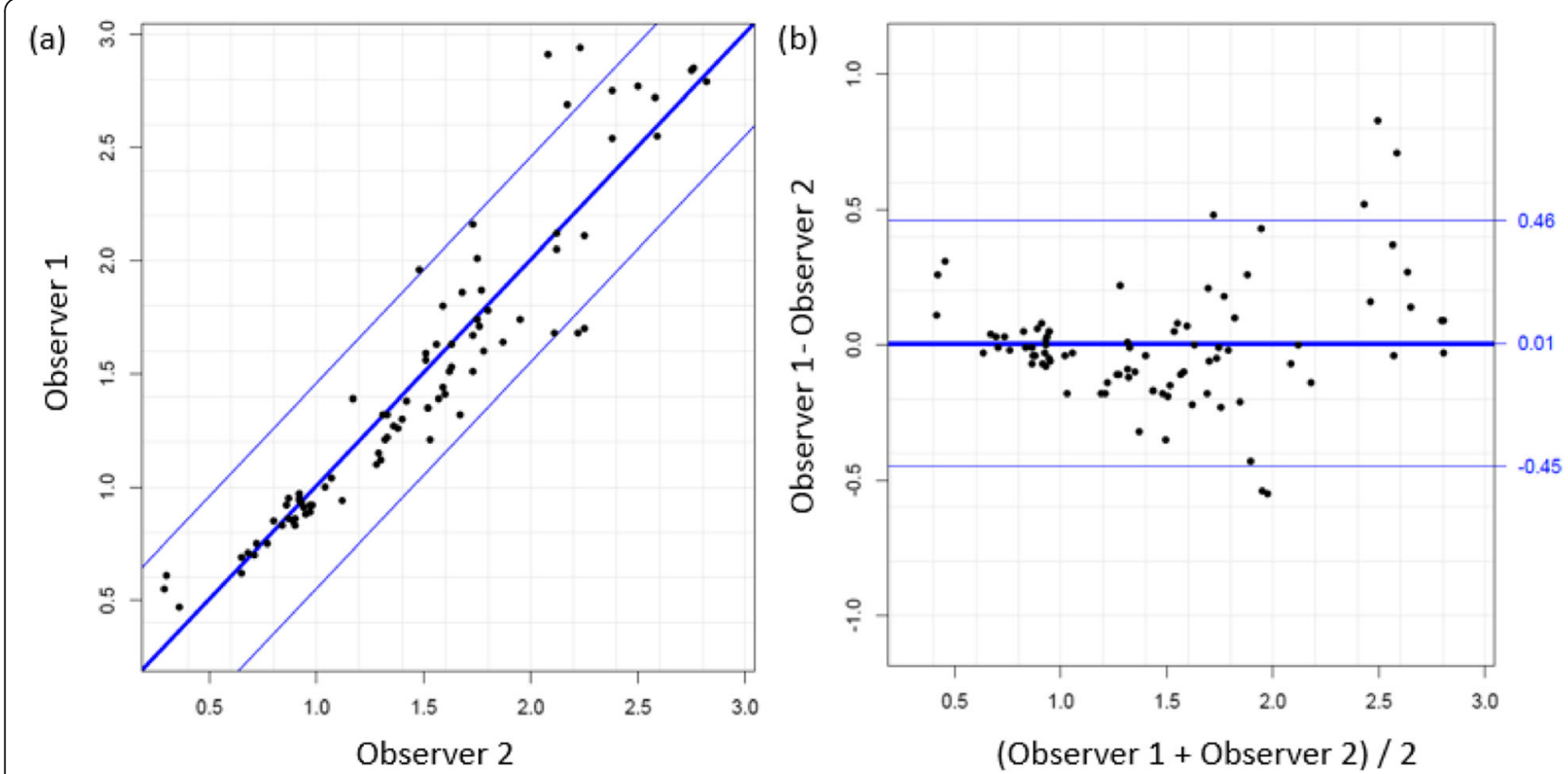

Fig. 3 a \& $\mathbf{b}$ Graphical comparisons of the measurements obtained for SAT by the two observers were made using Bland-Altman plots showing unlinked replicates (a). On the right; Plot of difference between measures of observer 1 and observer 2 against the mean of the two measurements of SAT (b). Solid line represents the mean; upper line shows the mean + 1.96 SD and lower line the mean - 1.96 SD

minimal for both measures falling within $95 \%$ confidence intervals.

Adipose tissue has been previously measured via various specific methodologies, to produce different indices including intra-abdominal fat, abdominal wall fat index, pre-peritoneal fat, mesenteric fat and several others.
These have been defined and characterised based on the specific anatomical sites utilized to measure them, as well as specific conditions such as fasting and breathe exhalation. As well as characterizing these methodologies, Bazzocchi et al., [3] compiles the work around the validation of these measures via ultrasound technique
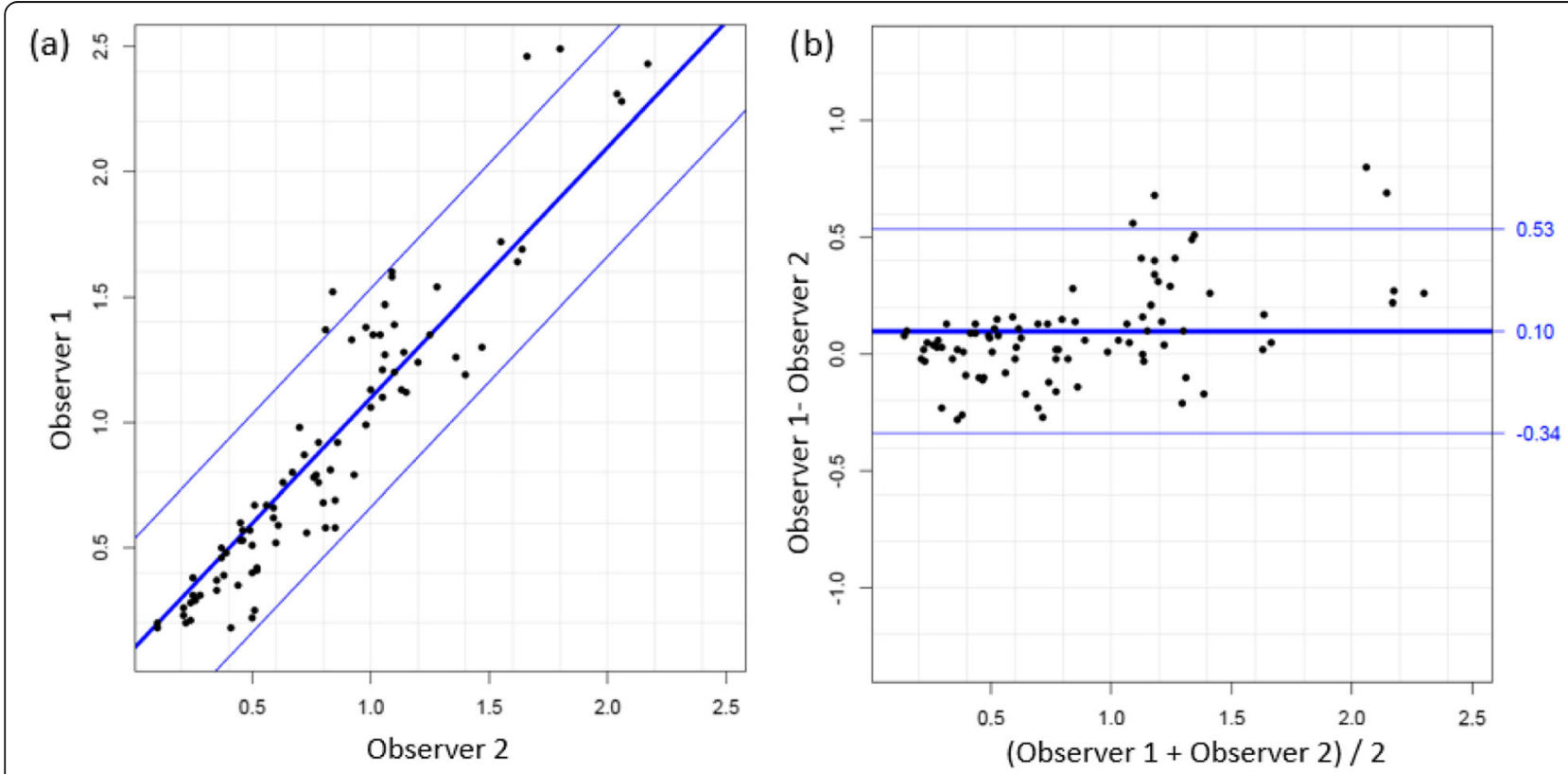

Fig. 4 a \& b Graphical comparisons of the measurements obtained for VAT by the two observers were made using Bland-Altman plots showing unlinked replicates (a). On the right; Plot of difference between measures of observer 1 and observer 2 against the mean of the two measurements of VAT (b). Solid line represents the mean; upper line shows the mean +1.96 SD and lower line the mean - 1.96 SD 
Table 2 Inter-observer repeatability SDs and repeatability coefficients (CV). SD: standard deviation of the difference between two measurements by the same method on the item under identical circumstances; the repeatability coefficient the numerical extent of the prediction interval for this difference, i.e. $2 *$ sqrt (2) *SD

\begin{tabular}{|c|c|c|c|c|c|c|}
\hline & \multicolumn{2}{|l|}{ SAT } & \multicolumn{2}{|l|}{ VAT } & \multicolumn{2}{|c|}{ Total adipose } \\
\hline & $\overline{S D}$ & $\mathrm{CV}$ & $\overline{S D}$ & $\mathrm{CV}$ & $\overline{S D}$ & $\mathrm{CV}$ \\
\hline Observer 1 & 0.079 & 0.157 & 0.087 & 0.174 & 0.122 & 0.245 \\
\hline Observer 2 & 0.107 & 0.215 & 0.128 & 0.256 & 0.155 & 0.310 \\
\hline
\end{tabular}

against the gold standard CT scanning and their reproducibility (intra -observer and inter- observer reliability). Pre-peritoneal fat thickness, (defined as the measurement taken on xiphoumbilical line just below the xiphoid process, as the major distance between the anterior surface of the peritoneum covering the liver lobe, to the posterior surface of the linea $a l b a$ ) is the specific abdominal adipose index measured in this study, and has been validated with success against $\mathrm{CT}$ imaging in recent times [8], demonstrated strong correlation between the CT imaging and US techniques (Lin's correlation coefficient of 0.85-0.87). Minimum Subcutaneous fat thickness (determined as the distance between the anterior surface of the linea alba and the peritoneum covering the liver lobe, in the same anatomical place of maximum preperitoneal fat thickness) also had excellent correlation with CT imaging (Lin's correlation coefficient of 0.94-0.96). Inter and intra-observer reliability has also been found to be very acceptable in obese and non-obese patients, with coefficients of variation reported between 4.3 and $6.4 \%[8,12]$. Reliability of these measures has never been tested in a pregnant population, and this is important as hydration of tissue changes during pregnancy, affects compressibility of tissues and therefore potentially introducing a source of error whilst undertaking measurements [31, 32]. Thus, this study contributes to this area of research in a population where the obesity epidemic is pertinent and timely.

The link between metabolic health and adiposity in pregnancy is currently a fertile ground of research [33-36]. Excessive accumulation of adipose tissue into the viscera, has been implicated in increased risk of cardio-metabolic risk [13, 37, 38] and diabetes mellitus $[13,38-40]$. Further to this, some studies have investigated measures of abdominal adipose tissue in early pregnancy, and established its ability to predict glucose intolerance and gestational diabetes in later pregnancy [41-46]. These research investigations give insight into how measures in early pregnancy can play an important role in earlier diagnosis and/or intervention, at a time when there is established contact with healthcare professionals [47]. Further to this, early detection of risk or diagnosis of gestational diabetes in pregnancy has been found to be critical in improving outcomes of various types of interventions, with dietary [48]; exercise [49]; pharmacological [50] intervention, as well a combination of these [51], showing improved outcomes when applied for a longer timespan.

The end of the first trimester (12 weeks gestation) is a clinically significant clinical time-point, at which women attend routine antenatal appointments to the maternity hospital to undertake an ultrasound scan to determine gestation, foetal number and to out-rule major foetal abnormalities. Following the scan the patient is booked in the Antenatal Clinic; medical and pregnancy history and any comorbidities are recorded and antenatal bloods are drawn. This 'booking visit' therefore presents a special opportunity of contact with healthcare staff which should be utilized effectively and efficiently to identify women at higher risk in order to improve management of disease.

However, this specific population is difficult to research with respect to obtaining ethical approval and consent due to concerns of invasive procedures during such a vulnerable period. The proposed US method to measure abdominal adipose is safe, non-invasive, economical, and does not involve any extra intervention for the patient- such as, specific procedural preparation. In addition, it is time-efficient, as it took the researchers less than 3 minutes to record three repeated measures on one person. We would recommend that future studies incorporate recording time taken to take the measurements. In practice, routine scans at antenatal visit are allocated $15 \mathrm{~min}$ each, despite variations according to clinical requirement. Future studies examining relationships between abdominal adiposity and pregnancy outcomes may prove to be clinically useful in terms of risk- stratification, therefore using US as a research tool will translate easily to an applicable tool in practice. Currently, body mass index is used as a risk-stratification tool during pregnancy; however, this does not capture body composition parameters such as abdominal adiposity, which are specifically implicated in metabolic health [11, 12, 20, 21].

\section{Conclusions}

Ultrasound is a non-invasive, safe, quick and available tool for quantifying adiposity in both clinical practice as a research tool. Standardized techniques for abdominal adiposity, specifically visceral fat thickness at the xiphoid region (pre-peritoneal fat) has not been previously investigated in a pregnant population, thus addressing a gap within the literature previously identified $[2,3]$. Therefore, this study offers a technique which when replicated, 
is a highly reliable and practical tool, which does not require demanding operator training and can therefore be implemented by researchers and clinicians during routine antenatal ultrasonography. Measurement of intraabdominal adipose by ultrasound is suitable for use in prospective observational or interventional studies in pregnant women.

\section{Abbreviations}

BMI: Body mass index; CT: Computed Tomography; CV: Coefficient of variation; DXA: Dual-energy X-ray absorptiometry; LoA: Limits of agreement; SAT: Subcutaneous adipose tissue; TGC: Time gain compensation; US: Ultrasound; VAT : Visceral adipose tissue; WHO: World Health Organisation

\section{Acknowledgements}

We would like to thank the pregnant women at the antenatal clinic at UMHL for their active participation in the study and all the staff of the Department of Ultrasonography for their patience whilst data was collected.

This research project was supported by the University of Limerick through an Education \& Health Sciences faculty Postgraduate Deans Scholarship, Graduate Entry Medical School Strategic Research Fund and Health Research Institute (HRI) Seed Funding from the University of Limerick.

\section{Authors' contributions}

ACr contributed to all aspects of research process and wrote the manuscript KC undertook statistical analysis. COG, $A D$ and $A C o$ are the supervisory team for PhD of $\mathrm{ACr}$. JH was part of team to secure funding stated above. $\mathrm{Kl}$ and CNL undertook the data collection of ultrasounds and contributed to the writing of methodology. All authors read and approved the manuscript.

\section{Funding}

This research project was supported by the University of Limerick through an Education \& Health Sciences faculty Postgraduate Deans Scholarship, Graduate Entry Medical School Strategic Research Fund and Health Research Institute Seed Funding from the University of Limerick.

\section{Availability of data and materials}

Data is available and can be accessed online in the supplementary material.

\section{Ethics approval and consent to participate}

Informed consent was sought and granted (REC 082/17) in accordance with the ethical recommendations of Health Service Executive (HSE) University Hospital Limerick committee on human research.

\section{Consent for publication}

Consent for publication is inherent in the ethics granted. More information available on request

\section{Competing interests}

The authors declare that they have no competing interests.

\section{Author details}

${ }^{1}$ Graduate Entry Medical School (GEMS), University of Limerick, Limerick Ireland. ${ }^{2}$ School of Allied Health (SAH), University of Limerick, Limerick, Ireland. ${ }^{3}$ Institute of Nutrition \& Dietetics (INDI), Dublin, Ireland. ${ }^{4}$ Health Research Institute (HRI), University of Limerick, Limerick, Ireland. ${ }^{5}$ Physical Education and Sport Sciences (PESS), University of Limerick, Limerick, Ireland. ${ }^{6}$ Department of Statistics, University College Cork (UCC), Cork, Ireland. ${ }^{7}$ University Maternity Hospital Limerick (UMHL), Limerick, Ireland. ${ }^{8}$ The Hospital for Sick Children, Toronto, Canada.

Received: 17 June 2019 Accepted: 8 November 2019

Published online: 17 December 2019

\section{References}

1. Armellini F, Zamboni M, Rigo L, Todesco T, Bergamo-Andreis IA, Procacci C, et al. The contribution of sonography to the measurement of intraabdominal fat. J Clin Ultrasound. 1990;18(7):563-7.
2. Wagner DR. Ultrasound as a tool to assess body fat. J Obes. 2013;2013: 280713.

3. Bazzocchi A, Filonzi G, Ponti F, Albisinni U, Guglielmi G, Battista G. Ultrasound: which role in body composition? Eur J Radiol. 2016;85(8):146980.

4. Seidell JC, Bakker CJ, van der Kooy K. Imaging techniques for measuring adipose-tissue distribution-a comparison between computed tomography and 1.5-T magnetic resonance. Am J Clin Nutr. 1990;51(6):953-7.

5. Berker D, Koparal S, Isik S, Pasaoglu L, Aydin Y, Erol K, et al. Compatibility of different methods for the measurement of visceral fat in different body mass index strata. Diagn Interv Radiol. 2010;16(2):99-105.

6. Armellini F, Zamboni M, Robbi R, Todesco T, Rigo L, Bergamo-Andreis IA, et al. Total and intra-abdominal fat measurements by ultrasound and computerized tomography. Int J Obes Relat Metab Disord. 1993;17(4):209-14.

7. Stolk RP, Wink O, Zelissen PM, Meijer R, van Gils AP, Grobbee DE. Validity and reproducibility of ultrasonography for the measurement of intra-abdominal adipose tissue. Int J Obes Relat Metab Disord. 2001;25(9):1346-51.

8. Bazzocchi A, Filonzi G, Ponti F, Sassi C, Salizzoni E, Battista G, et al. Accuracy, reproducibility and repeatability of ultrasonography in the assessment of abdominal adiposity. Acad Radiol. 2011;18(9):1133-43.

9. Robič T, Benedik E, Mis NF, Bratanič B, Rogelj I, Golja P. Challenges in determining body fat in pregnant women. Ann Nutr Metab. 2014;63(4):341-9.

10. Most J, Marlatt KL, Altazan AD, Redman LM. Advances in assessing body composition during pregnancy. Eur J Clin Nutr. 2018;72(5):645-56.

11. Despres JP, Lemieux I. Abdominal obesity and metabolic syndrome. Nature. 2006;444(7121):881-7.

12. Hamagawa K, Matsumura Y, Kubo T, Hayato K, Okawa M, Tanioka K, et al. Abdominal visceral fat thickness measured by ultrasonography predicts the presence and severity of coronary artery disease. Ultrasound Med Biol. 2010; 36(11):1769-75.

13. Bartha JL, Marin-Segura P, Gonzalez-Gonzalez NL, Wagner F, AguilarDiosdado M, Hervias-Vivancos B. Ultrasound evaluation of visceral fat and metabolic risk factors during early pregnancy. Obesity (Silver Spring, Md). 2007:15(9):2233-9.

14. Cedergren Ml. Maternal morbid obesity and the risk of adverse pregnancy outcome. Obstet Gynecol. 2004;103(2):219-24.

15. Dodd JM, Grivell RM, Nguyen AM, Chan A, Robinson JS. Maternal and perinatal health outcomes by body mass index category. Aust N Z J Obstet Gynaecol. 2011;51(2):136-40.

16. World Health Organization. Obesity; Preventing and Managing the Global Epidemic. Geneva: WHO; 2003.

17. Scott-Pillai R, Spence D, Cardwell CR, Hunter A, Holmes VA. The impact of body mass index on maternal and neonatal outcomes: a retrospective study in a UK obstetric population, 2004-2011. BJOG. 2013;120(8):932-9.

18. Catalano PM, Mclntyre HD, Cruickshank JK, McCance DR, Dyer AR, Metzger BE, et al. The hyperglycemia and adverse pregnancy outcome study: associations of GDM and obesity with pregnancy outcomes. Diabetes Care. 2012:35(4):780-6.

19. Wahabi HA, Fayed AA, Alzeidan RA, Mandil AA. The independent effects of maternal obesity and gestational diabetes on the pregnancy outcomes. BMC Endocr Disord. 2014;14:47

20. Kirwan JP, Hauguel-De Mouzon S, Lepercq J, Challier JC, Huston-Presley L, Friedman JE, et al. TNF-a is a predictor of insulin resistance in human pregnancy. Diabetes. 2002:51(7):2207-13.

21. Jayabalan N, Nair S, Nuzhat Z, Rice GE, Zuniga FA, Sobrevia L, et al. Cross talk between adipose tissue and placenta in obese and gestational diabetes mellitus pregnancies via Exosomes. Front Endocrinol. 2017:8:239.

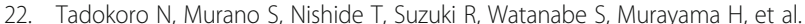
Preperitoneal fat thickness determined by ultrasonography is correlated with coronary stenosis and lipid disorders in non-obese male subjects. Int J Obes. 2000;24(4):502-7.

23. Tayama K, Inukai T, Shimomura Y. Preperitoneal fat deposition estimated by ultrasonography in patients with non-insulin-dependent diabetes mellitus. Diabetes Res Clin Pract. 1999;43(1):49-58.

24. Yamamoto M, Equsa G, Hara H, Yamakido M. Association of intraabdominal fat and carotid atherosclerosis in non-obese middle-aged men with normal glucose tolerance. Int J Obes. 1997:21(10):948-51.

25. Porter SA, Massaro JM, Hoffmann U, Vasan RS, O'Donnel CJ, Fox CS Abdominal subcutaneous adipose tissue: a protective fat depot? Diabetes Care. 2009;32(6):1068-75.

26. Patel $\mathrm{P}$, Abate $\mathrm{N}$. Role of subcutaneous adipose tissue in the pathogenesis of insulin resistance. J Obes. 2013;2013:489187. 
27. Bazzocchi A, Filonzi G, Ponti F, Amadori M, Sassi C, Salizzoni E, et al. The role of ultrasonography in the evaluation of abdominal fat: analysis of technical and methodological issues. Acad Radiol. 2013;20(10):1278-85.

28. Bland JM, Altman DG. Applying the right statistics: analyses of measurement studies. Ultrasound Obstet Gynecol. 2003;22(1):85-93.

29. Carstensen B, Gurrin L, Ekstrom C, Figurski M. MethComp: Functions for Analysis of Agreement in Method Comparison Studies. R package version 1. 22.2. 2015 ed2015.

30. Carstensen B. Comparing clinical measurement methods: a practical guide: Wiley; 2010. https://doi.org/10.1002/9780470683019.

31. Taggart NR, Holliday RM, Billewicz WZ, Hytten FE, Thomson AM. Changes in skinfolds during pregnancy. Br J Nutr. 1967;21(2):439-51.

32. van Raaij JM, Peek ME, Vermaat-Miedema SH, Schonk CM, Hautvast JG. New equations for estimating body fat mass in pregnancy from body density or total body water. Am J Clin Nutr. 1988;48(1):24-9.

33. Tumurbaatar B, Poole AT, Olson G, Makhlouf M, Sallam HS, Thukuntla S, et al. Adipose tissue insulin resistance in gestational diabetes. Metab Syndr Relat Disord. 2017;15(2):86-92.

34. Svensson $\mathrm{H}$, Wetterling $\mathrm{L}$, Andersson-Hall U, Jennische $\mathrm{E}$, Eden $\mathrm{S}$, Holmang A, et al. Adipose tissue and body composition in women six years after gestational diabetes: factors associated with development of type 2 diabetes. Adipocyte. 2018;7(4):229-37.

35. Selovic A, Belci D. Influence of distribution of mother's abdominal body fat on first trimester fetal growth. J Matern Fetal Neonatal Med. 2018;31:1-6.

36. Bi $X$, Loo YT, Henry CJ. Ultrasound measurement of intraabdominal fat thickness as a predictor of insulin resistance and low HDL cholesterol in Asians. Nutrition. 2018;55-56:99-103.

37. Ribeiro-Filho FF, Faria AN, Kohlmann O Jr, Ajzen S, Ribeiro AB, Zanella MT, et al. Ultrasonography for the evaluation of visceral fat and cardiovascular risk. Hypertension. 2001;38(3 Pt 2):713-7.

38. Vlachos IS, Hatziioannou A, Perelas A, Perrea DN. Sonographic assessment of regional adiposity. AJR Am J Roentgenol. 2007;189(6):1545-53.

39. Neeland IJ, Turer AT, Ayers CR, Powell-Wiley TM, Vega GL, Farzaneh-Far R, et al. Dysfunctional adiposity and the risk of prediabetes and type 2 diabetes in obese adults. JAMA. 2012;308(11):1150-9.

40. Bray GA, Jablonski KA, Fujimoto WY, Barrett-Connor E, Haffner S, Hanson RL, et al. Relation of central adiposity and body mass index to the development of diabetes in the diabetes prevention program. Am J Clin Nutr. 2008;87(5):1212-8.

41. Gur EB, Ince O, Turan GA, Karadeniz M, Tatar S, Celik E, et al, Ultrasonographic visceral fat thickness in the first trimester can predict metabolic syndrome and gestational diabetes mellitus. Endocrine. 2014; 47(2):478-84.

42. Martin AM, Berger H, Nisenbaum R, Lausman AY, MacGarvie S, Crerar C, et al. Abdominal visceral adiposity in the first trimester predicts glucose intolerance in later pregnancy. Diabetes Care. 2009;32(7):1308-10.

43. De Souza LR, Kogan E, Berger H, Alves JG, Lebovic G, Retnakaran R, et al. Abdominal adiposity and insulin resistance in early pregnancy. J Obstet Gynaecol Can. 2014;36(11):969-75.

44. D'Ambrosi F, Crovetto F, Colosi E, Fabietti I, Carbone F, Tassis B, et al. Maternal subcutaneous and visceral adipose ultrasound thickness in women with gestational diabetes mellitus at 24-28 Weeks' gestation. Fetal Diagn Ther. 2018;43(2):143-7.

45. Yang SH, Kim C, An HS, An H, Lee JS. Prediction of gestational diabetes mellitus in pregnant Korean women based on abdominal subcutaneous fat thickness as measured by ultrasonography. Diabetes Metabol J. 2017;41(6): 486-91.

46. Bourdages M, Demers ME, Dube S, Gasse C, Girard M, Boutin A, et al. Firsttrimester abdominal adipose tissue thickness to predict gestational diabetes. J Obstet Gynaecol Can. 2018;40(7):883-7.

47. Poon LC, Mclntyre HD, Hyett JA, da Fonseca EB, Hod M. The first-trimester of pregnancy - a window of opportunity for prediction and prevention of pregnancy complications and future life. Diabetes Res Clin Pract. 2018;145:20-30.

48. Thangaratinam S, Rogozinska E, Jolly K, Glinkowski S, Roseboom T, Tomlinson JW, et al. Effects of interventions in pregnancy on maternal weight and obstetric outcomes: meta-analysis of randomised evidence. BMJ. 2012;344:e2088.

49. Cremona A, O'Gorman C, Cotter A, Saunders J, Donnelly A. Effect of exercise modality on markers of insulin sensitivity and blood glucose control in pregnancies complicated with gestational diabetes mellitus: a systematic review. Obes Sci Pract. 2018;4(5):455-67.
50. Syngelaki A, Nicolaides KH, Balani J, Hyer S, Akolekar R, Kotecha R, et al. Metformin versus placebo in obese pregnant women without diabetes mellitus. N Engl J Med. 2016;374(5):434-43.

51. Koivusalo SB, Rono K, Klemetti MM, Roine RP, Lindstrom J, Erkkola M, et al. Gestational diabetes mellitus can be prevented by lifestyle intervention: the Finnish gestational diabetes prevention study (RADIEL): a randomized controlled trial. Diabetes Care. 2016;39(1):24-30.

\section{Publisher's Note}

Springer Nature remains neutral with regard to jurisdictional claims in published maps and institutional affiliations.
Ready to submit your research? Choose BMC and benefit from:

- fast, convenient online submission

- thorough peer review by experienced researchers in your field

- rapid publication on acceptance

- support for research data, including large and complex data types

- gold Open Access which fosters wider collaboration and increased citations

- maximum visibility for your research: over $100 \mathrm{M}$ website views per year

At BMC, research is always in progress.

Learn more biomedcentral.com/submissions 